\title{
Enhancement of nutritional and antioxidant properties of brown rice flour through solid-state yeast fermentation
}

\begin{abstract}
This study investigated the effect of solid-state yeast fermentation on the nutritional and antioxidant properties of brown rice flour (BRF). Three brands of commercial baker's yeast (Eagle, Saf-levure, and Mauripan) were used to ferment BRF at $25^{\circ} \mathrm{C}$ for $12 \mathrm{~h}$. There were significant increases in protein, ash, insoluble and soluble fiber, phosphorus, zinc, magnesium, calcium, and iron contents after yeast fermentation. Fermented BRF with Eagle yeast possessed the highest contents of protein, ash, zinc, and calcium. Fermentation of BRF with Eagle yeast was more effective in increasing antioxidant activity and total phenolic contents from 1.01 to $1.54 \mathrm{mmol}$ of Trolox equivalents per gram and from 1.09 to $1.21 \mathrm{mg}$ of gallic acid equivalents per gram, respectively. Yeast fermentation reduced phytic acid content of BRF $(124.59 \pm 0.48 \mu \mathrm{g} / \mathrm{g})$, and the Eagle yeast-fermented sample had the lowest value (36.55 $\mu \mathrm{g} / \mathrm{g}$ ) compared with the other fermented samples. Fermented flour with Eagle yeast also had the highest $\alpha$-amylase activity, because it recorded the lowest stirring number. Solidstate fermentation with commercial yeast, particularly Eagle yeast, was effective in improving the nutritional and antioxidant properties of underutilized BRF as a food ingredient.
\end{abstract}

Keyword: Nutritional; Antioxidant; Brown rice flour; Solid-state yeast; Fermentation 